\section{A Rare Finding of Upper Limb Deep Venous Thrombosis in a Patient with COVID-19}

Sir,

Patients with COVID-19 are currently considered at high risk of developing thromboembolic complications. The use ofanticoagulants at higher than routine prophylactic doses may be considered to reduce the risk of thromboembolic events.

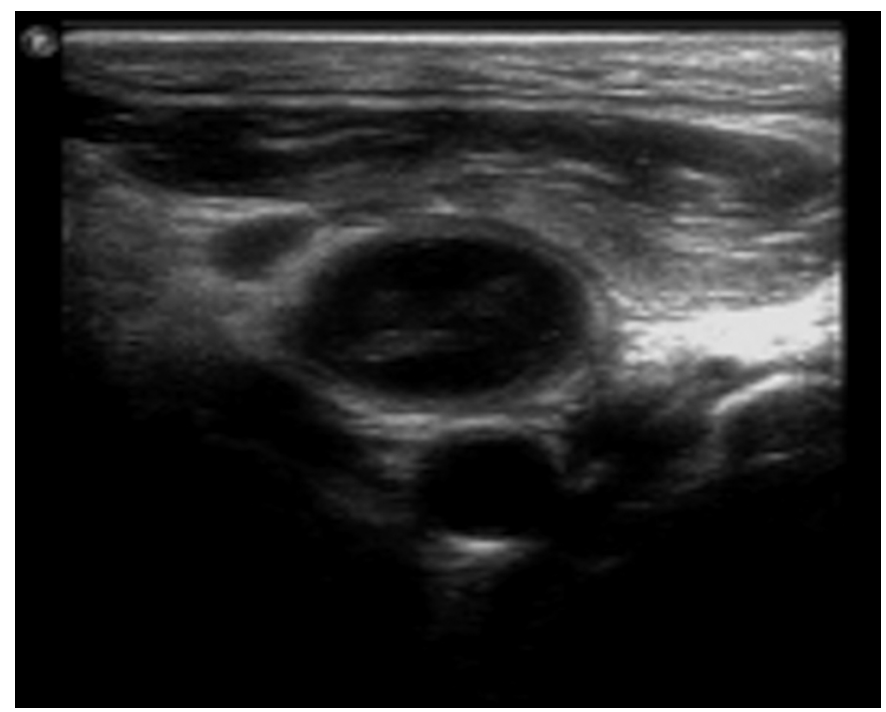

Figure 1: Transverse axis view of right neck: IJ right Internal jugular vein with hyperechoic focus representing thrombosis partially obstructing the IJ on ultrasound duplex, C right carotid artery.

Studies on COVID-19 patients with severe SARS-CoV-2 pneumonia have shown an increased risk of both venous and arterial thromboembolic events with an incidence of up to $30 \%{ }^{1,2}$ Although, the pathological evidence is rudimentary, but these patients demonstrate a hypercoagulable state with elevated Ddimer levels, hyper-ferritinemia, and hyper-fibrinogenemia. Despite the lack of prospective studies to date, experts are currently recommending the use of low molecular weight heparin at twice the usual dose, at least, in those with severe COVID-19. ${ }^{3}$ Clinical experience suggests that this coagulopathy is associated with an increased risk for both venous and arterial thrombosis. ${ }^{4}$ We wish to highlight a rare complication of upper limb deep venous thrombosis (DVT) in a 53-year male admitted with severe SARS-COV-2 infection, who required continued mechanical ventilation for 18 days with deep sedation, intermittent muscle relaxation and several sessions of proning as part of management. During his stay in our COVID intensive care unit (ICU), he developed hypercoagulable state (Table I), that was managed and monitored accordingly. CT pulmonary angiography was done on day $9^{\text {th }}$ day of admission to rule out pulmonary embolism due to high D-dimers, butwas negative.
Table I: Coagulation parameters of the patient during the course of COVID-19illness.

\begin{tabular}{|c|c|c|c|c|c|}
\hline $\begin{array}{l}\text { Day of ICU } \\
\text { Admission }\end{array}$ & PT & INR & Fibrinogen & D-Dimer & Comments \\
\hline D1 & 15.6 & 1.3 & 6.4 & 0.67 & \\
\hline D4 & 16.2 & 1.4 & 7.2 & 3.55 & \\
\hline D7 & 14.8 & 1.3 & 2.9 & $>5.0$ & $\begin{array}{c}\text { Therapeutic } \\
\text { anticoagulation } \\
\text { with enoxaparin } \\
40 \text { mg BD sub- } \\
\text { cutaneous started. }\end{array}$ \\
\hline D9 & 25.3 & 2.2 & 1.2 & $>5.0$ & $\begin{array}{l}\text { CT P.A negative for } \\
\text { Pulmonary embolism. } \\
\text { (It could not be done } \\
\text { earlier because of } \\
\text { high ventilatory } \\
\text { requirements along } \\
\text { with high doses of } \\
\text { vasopressor and } \\
\text { inotropes) } \\
\text { Vitamin K 10mg } \\
\text { given I.V }\end{array}$ \\
\hline D12 & 12.1 & 1.0 & 2.4 & 3.0 & \\
\hline D17 & 12.4 & 1.1 & 3.9 & 2.5 & \\
\hline D22 & 11 & 1.0 & 3.0 & 3.09 & $\begin{array}{l}\text { Evidence of upper } \\
\text { limb DVT (detail } \\
\text { description given in } \\
\text { case description) }\end{array}$ \\
\hline D23 & 12.5 & 1.1 & NA & NA & \\
\hline D24 & 12.5 & 1.1 & NA & NA & \\
\hline D30 & 12.1 & 1.0 & 4.0 & 1.01 & \\
\hline D38 & 11.5 & 1.0 & 2.3 & 0.28 & \\
\hline
\end{tabular}

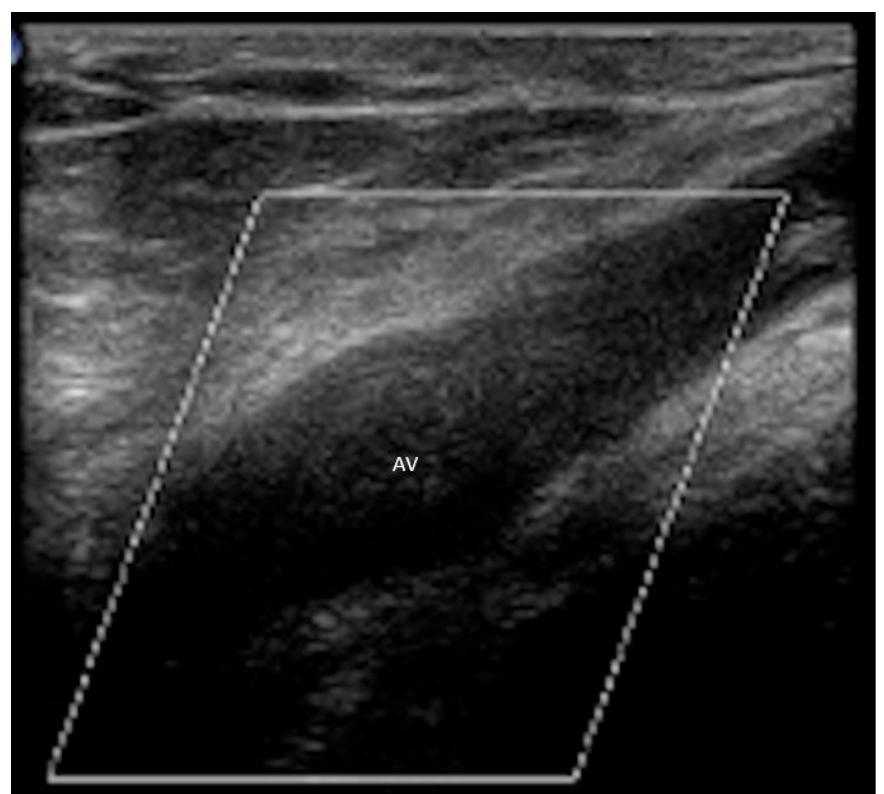

\section{Right Axillary $\mathrm{V}$ Long}

Figure 2: Long axis view of right Arm: AV right axillary vein with hyperechoic focus representing thrombosis significantly obstructing the AV on ultrasound duplex.

Following a gradual improvement in ventilatory parameters, he was extubated on the morning of $19^{\text {th }}$ day of admission. Soon after extubation, he complained about right upper arm pain. Superficial edema of the arm was appreciated, but there was no evidence of redness and elevated temperature of the area. Initially, we consid- 
ered a possibility of pressure-induced skin erythema due to frequent proning; but a Doppler ultrasound of upper arm was done to rule out vascular involvement, which revealed DVT of the upper limb. There was occlusive thrombus within the right internal jugular vein, subclavian vein, right axillary vein and extending to the right brachial vein as shown in Figures 1 to 3 . Superficial basilic and cephalic veins were patent. Consultation for haematology was organised and therapeutic anticoagulation with subcutaneous enoxaparin $40 \mathrm{mg}$ B.D was continued along with aspirin for prophylaxis. Right arm swelling and pain gradually resolved over nextfew days.

A hypercoagulable sate is noted in many of these patients which can manifest in different ways like stroke, infarct, and vascular thrombosis. ${ }^{5}$ Thus, there is a need to consider DVT in differential diagnosis of upper or lower limbswelling and manage it accordingly.

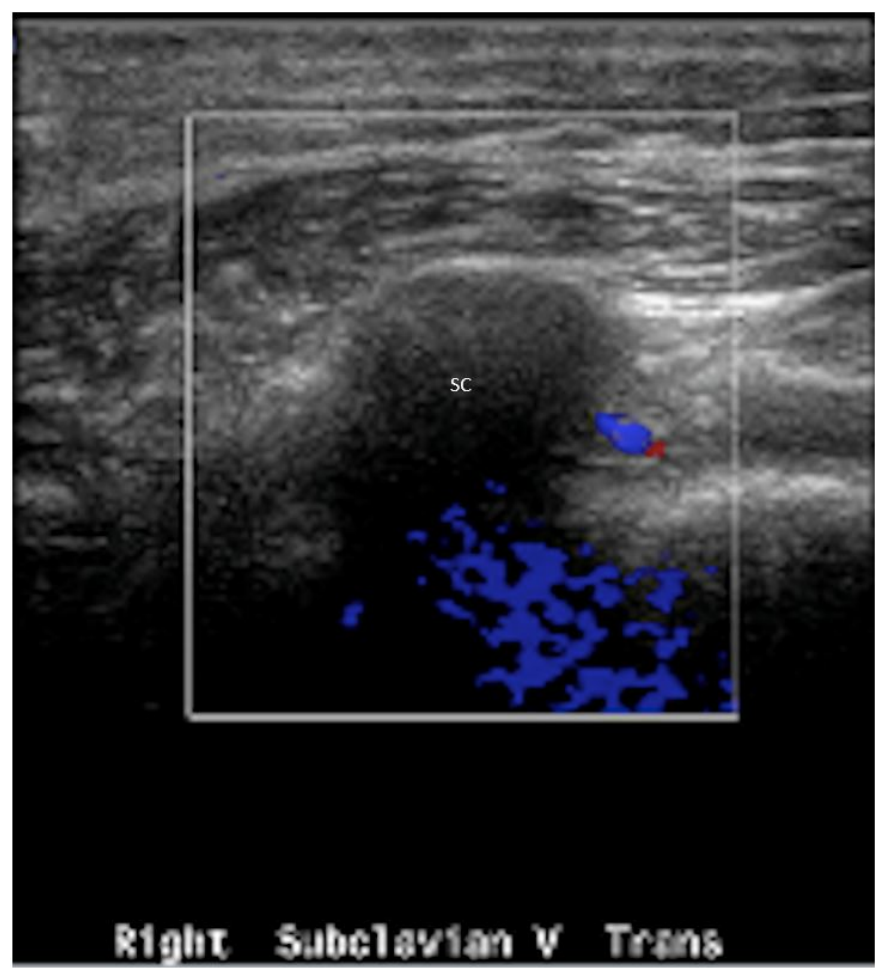

Figure 3: Transverse axis view of right lower neck: SC right subclavian vein with hyperechoic focus representing thrombosis significantly obstructing the SC on ultrasound duplex. Colour doppler shows there is crucially decreased flow at the thrombus.

\section{CONFLICT OF INTREST:}

Authors declared no conflict of interest.

\section{AUTHORS' CONTRIBUTION:}

SL: Retrieved data of patients and authored manuscript.

$\mathrm{JH}$ : Provided idea of reporting the complication and helped in drafting.

\section{REFERENCES}

1. Klok FA, Kruip MJHA, Van der Meer NJM, Arbous MS, Gommers DAMPJ, Kant KM, et al. Incidence of thrombotic complications in critically ill ICU patients with COVID-19. Thromb Res 2020; 191:145-7.

2. Helms I, Tacquard C, Severac F, Leonard-Lorant I, Ohana M, Delabranche $X$, et al. High risk of thrombosis in patients with severe SARS-CoV-2 infection: A multicenter prospective cohort study. Intensive Care Med 2020; 46(6):1089-98.

3. Tang N, Bai H, Chen X, Gong J, Li D, Sun Z. Anticoagulant treatment is associated with decreased mortality in severe coronavirus disease 2019 patients with coagulopathy. J Throm Haemos 2020; 18(5):1094-9.

4. Bikdeli B, Madhavan MV, Jimenez D, Chuich T, Dreyfus I, Driggin E, et al. COVID-19 and thrombotic or thromboembolic disease: Implications for prevention, antithrombotic therapy, and follow-up. J Am Coll Cardiol 2020; 75(23):2950-73.

5. Llitjos JF, Leclerc $M$, Chochois C, Monsallier JM, Ramakers $M$, Auvray $M$, et al. High incidence of venous thromboembolic events in anticoagulated severe COVID-19 patients. J Throm Haemos 2020; $10.1111 /$ jth.

Shankar Lal and Junaid Hashmi

Department of Anaesthesia and Critical Care Medicine, Our Lady of Lourdes Hospital, Drogheda, Republic of Ireland

Correspondence to: Dr. Shankar Lal, Department of Anaesthesia and Critical Care Medicine, Our Lady of Lourdes Hospital, Drogheda, Republic of Ireland E-mail: shankar.anaesthesia1@gmail.com

Received: May 28, 2020; Revised: June 18, 2020; Accepted: June 23, 2020

DOI: https://doi.org/10.29271/jcpsp.2020.JCPSPCR.CR76 